\title{
Is review of enriched populations the way forward for glaucoma case detection?
}

Eye (2003) 17, 5-6. doi:10.1038/sj.eye.6700262

In the United Kingdom, we rely on High Street optometrists to detect and refer the vast majority of new cases of primary open angle glaucoma for therapy. This case-finding process is clearly crucial to the provision of quality ophthalmic care to our community and should be the subject of ongoing scrutiny and research. In this month's Eye, Henson et al have done just that. They report the impact of a new initiative in the first assessment of individuals with suspect glaucoma detected by such community optometrists. ${ }^{1}$

In interpreting the results of such studies, it is helpful to review the basic epidemiological principles of such a case-finding process. Glaucoma is a relatively rare disease affecting between 1 and $2 \%$ of those aged over 40 years in Caucasian populations, ${ }^{2-4}$ with a similar prevalence in Indian populations ${ }^{5}$ and greater prevalence in African and Caribbean populations. ${ }^{3,6,7}$ Nonetheless it is of public health importance. Despite under-reporting of those blind as a result of the disease, ${ }^{8}$ glaucoma remains the most common cause of preventable blind registration in the elderly in this country.

If a population of 10000 with a prevalence of $2 \%$ is tested for glaucoma using a test with $97 \%$ specificity and $97 \%$ sensitivity, one would expect 194 glaucoma cases to be detected and six to be missed. In addition, 294 individuals would be identified as false positive cases. Thus, of 488 referrals to the hospital, $40 \%$ would have glaucoma, a figure approximating that found in many hospital-based studies. ${ }^{9,10}$ Even the most enthusiastic reports of diagnostic tests for glaucoma do not often achieve such high sensitivities and specificities and yet there is often an implication that the optometric community performs poorly in this respect. ${ }^{11}$

I Murdoch and J Theodossiades

Henson et al report the use of 'accredited optometrists' to review all referrals by community optometrists, thus lightening the load on the hospital department. They show that the percentage of referrals discharged by the accredited optometrists as false positives is similar to the proportion of false positives found at Manchester Royal Eye prior to the study. This is an exciting result and we look forward to the longer-term results of this initiative. Care must be taken, before assuming what this result is attributable to. It may be purely a function of the enriched population examined by the accredited optometrists. If the prevalence in a population increases and the testing efficiency remains constant, the accuracy of referral will increase. If the accredited optometrists reassess the 488 referrals from the example above, the optometrists are in reality testing a population that has been selected and has a prevalence of $40 \%$ glaucoma (194 cases). If the same testing efficiency of $97 \%$ sensitivity and specificity is applied, then 188 cases will be identified with only nine (3\% of 294) false positives. This means $188 / 197=95 \%$ referral accuracy.

Thus, an improvement in referral accuracy is not necessarily the result of better patient examination or decision-making by the accredited optometrists, but may be explained by epidemiological principles.

The issue of false negatives should also not be overlooked. With the serial approach to glaucoma case finding used in the Henson et al model, there is potential for an increase in the number of false negatives. Using the above examples, six cases of glaucoma were missed in the initial testing of the population of 10000 , and a further six missed by the accredited optometrists. When assessing an enriched
Moorfields Eye Hospital City Road

London ECIV 2PD, UK

Correspondence:

I Murdoch

Tel: +44 2075662059

Fax: +44 20772503207

E-mail: iemurdoch@

compuserve.com 
population, test sensitivity needs to be maximised to keep numbers of missed glaucoma low. This would be the principal case for the accreditation process for the optometrists in the Henson et al model.

Although it is accepted that to improve the quality of glaucoma case finding, the accuracy of glaucoma referrals needs to improve, this must not be at the expense of numbers of glaucoma cases detected. Only half of our glaucoma cases in the community are detected and receiving therapy in the developed world. ${ }^{2-4}$ To achieve improved case detection, more comprehensive testing strategies with confirmation of positive findings, should be adopted as in the Henson et al study rather than simply using stricter referral criteria.

The above principles need to inform a wider discussion. What is society's view concerning the issue of false-negative glaucoma test results? What are the legal implications? What is the balance between service costs and proportion of cases receiving treatment?

These and many other each questions need to be discussed and researched as we plan future ophthalmic eye care provision in the United Kingdom.

\section{References}

1 Henson DB, Spencer AF, Harper R, Cadman EJ. Community refinement of glaucoma referrals. Eye 2003; 17: 21-26.
2 Coffey M, Reidy A, Wormald R, Xian WX, Wright L, Courtney P. Prevalence of glaucoma in the west of Ireland. Br J Ophthalmol 1993; 77: 17-21.

3 Tielsch JM, Sommer A, Katz J, Royall RM, Quigley HA Javitt J. Racial variations in the prevalence of primary open angle glaucoma: the Baltimore Eye Survey. JAMA 1991; 266(3): 369-374.

4 Mitchell P, Smith W, Attebo K, Healey PR. Prevalence of open-angle glaucoma in Australia: the Blue Mountains Eye Study. Ophthalmology 1996; 103: 1661-1669.

5 Dandona L, Dandona R, Srinivas M, Mandal P, John RK, McCarty CA, Rao GN. Open-angle glaucoma in an urban population in southern India: the Andhra Pradesh eye disease study. Ophthalmology 2000; 107: 1702-1709.

6 Leske MC, Connell AMS, Schachat AP, Hyman L. The Barbados eye study: prevalence of open angle glaucoma. Arch Ophthalmol 1994; 112: 821-829.

7 Buhrmann RR, Quigley HA, Barron Y, West SK, Oliva MS, Mmbaga BB. Prevalence of glaucoma in a rural East African population. Invest Ophthalmol Visual Sci 2000; 41: 40-48.

8 Bunce C, Evans J, Fraser S, Wormald R. BD 8 certification of visually impaired people. $\mathrm{Br}$ J Ophthalmol 1998; 82: 72-76.

9 Bell RWD, O'Brien C. Accuracy of referral to a glaucoma clinic. Ophthal Physiol Opt 1997; 17: 7-11.

10 Sheldrick JH, Ng C, Austin DJ, Rosethal AR. An analysis of referral routes diagnostic accuracy in cases of suspected glaucoma. Ophthal Epidemiol 1994; 1: 31-39.

11 Vernon SA. The changing pattern of glaucoma referrals by optometrists. Eye 1998; 12: 854-857. 